\title{
My view on change in architectural education
}

\author{
Richard L. Hayes, PhD. AIA
}

Director, American Institute of Architects

Saffo, Paul, "Get Ready for a New Economic Era," What Matters, McKinsey \& Company. http://whatmatters.mckinseydigital.com/internet/ get-ready-for-a-new-economic-era

Architectural education should be a scholarly adventure exploring the art of proportion and order coupled with an administration that supports an enriched ecology of the human spirit.

In order to accomplish desired change, there needs to be a continual pursuit by a vibrant, enjoyable learning community rallying to a core belief. This core belief must contain a common value such as that each of us can make a difference. By teaching values, skills, and practices that underlie such a notion as making a difference, architecture learning environments are created that resonate.

The learning environment needs to have administrative centralism around excelling in teaching, research, service to the community. Teachers should be focused on how to compel learning, not pushing arcane agendas. All the players concerned with constructing visions should be included - no matter how humble they are as research partners. Devotion of service to the community does not come easy to some, but there must be an environment created that promotes striving for this goal.

Teaching serves as the primary means of integrating all meaningful architectural design issues; the social, technological, environmental, cultural, organization and design. People need to take responsibility for designing our future through an enhanced perception of these issues. The study of architecture in light of these issues needs to be tempered with research and the world of practice. Evidence based discoveries and internships should be a supplement in reaching a meaningful architectural education.

Programs in architecture should value collaboration and be a noncompetitive but rigorous learning environment. This includes stressing intellectual inquiry as a basis for design exploration without dictating a specific design ideology or aesthetic. Developing leaders in issues of environmental sustainability, including the design of buildings, interiors, and communities requires critical thinkers who will feel empowered to take future innovation positions in the profession.
In summary what competencies do I consider to be the most important for success of the premise effectively implementing change in architectural education? They would be: return to the basics of being a good teacher, communicate ideas that can be critically tested, employ management that is participative, change supervision to ensure viability, and quest for critical feedback.

Key to all of the above is having administrations that keep a comprehensive well shared master plan at the forefront of thought, longterm realist fiscal management and maintaining a culture of trust through effective communication. 